\title{
Levantamento do Perfil do aluno no Ensino a Distáncia: Processo e Aplicaçóes
}

\author{
(Student Profile Identification in Distance \\ Learning put into Practice)
}

NELLY MOULIN ANDRÉ MONAT

\author{
Universidade Salgado de Oliveira - UNIVERSO \\ (Brasil)
}

\begin{abstract}
RESUMO: O propósito do artigo é apresentar a sistemática de levantamento do perfil sócio-cultural e educacional do aluno adotada, desde a década de 80, por professores que trabalham como tutores nos cursos de pósgraduaçao lato sensu (especializaçao) a distáncia, no modalidade semi-presencial, da Universidade Salgado de Oliveira UNIVERSO. Além de possibilitar a oferta de um tratamento diferenciado, ao identificar os conhecimentos já dominados pelo aluno, o perfil académico permite que o ensino comece a partir desse ponto em direçao a uma real ampliaçao de conhecimentos. Informaçoes fornecidas pelos alunos sobre o contexto e os problemas que ocorran no ámbito profissionai, também contribuem para tornar mais efetiva a açáo da tutoria. $O$ artigo descreve o modo como é feito o levantamento do perfil, os seus objetivos, $e$ sugere diversas formas de aplicaçáo dos dados e informaçóes obtidas.
\end{abstract}

\section{Perfil sócio-cultural do aluno no ensino a distáncia - perfil académico do aluno no ensino a distáncia - identificaçao do perfil do aluno no ensino a distancia.}

\begin{abstract}
The purpose of this paper is to present the procedures used by distance education tutors at the University Salgado de Oliveira - UNIVERSO, when they raise the social-cultural and educational profile of their students. Such profile is used to adjust the instructional material and the content of the course. Therefore, the whole course flts the student context and his/her intellectual level and interests. This procedure produce many beneflts. First, it identifles previously acquired knowledge by the students. This allows designing distance learning courses for teaching unknown issues for them. Obviously, this provides a real enlargement of knowledge. Second, description of the student context and their recurrent professional problems has shown to be a helpful aid to make tutorial processes more effective. The article describes the process of surveying the student profile and suggests several ways to take advantage of the data collected.
\end{abstract}




\section{Student social-cultural profile in distance learning; student academic profile in distance learning; identification of the student profile in distance learning.}

\section{INTRODUÇÁO}

Nos anos 70, um movimento de renovaçáo da Educaçáo denunciava o caráter reprodutivista do ensino formal, cuja funçao seria a de reproduzir as condiçóes da sociedade vigente, e clamava por urna prática pedagógica mais coerente com a realidade sócio-cultural do aluno (Bourdieu \& Passeron, 1975).

De acordo com essa teoria, mantida pela sociedade, a Educaçao só pode ser compreendida a partir dos condicionantes sociais e das relaçóes de dependéncia para com as forças dominantes da sociedade que a mantém. Várias correntes, denominadas por Saviani (1983) de Crítico-Reprodutivistas, tentavam explicar a dinámica das funçóes sociais da educaço e da escola, estando entre as principais: a teoria do sistema de ensino enquanto violéncia simbólica (Bourdieu \& Passeron, 1975); a teoria da escola enquanto aparelho ideológico do estado (Althusser, s/d); e a teoria da escola dualista (Baudelot e Establet, 1971).

Prevalecendo essas teses, seria irnpossível considerar que açóes pedagógicas da escola pudessem contribuir para superar as desigualdades sociais. Entretanto, dentre as teses surgidas naquele momento, predominou a visáo da relaço dialética existente entre educaçáo escolar e sociedade, isto é, a educaço escolar é, a um só tempo, produto e fator da sociedade. Por um lado, a escola é a forma institucionalizada de transmitir o saber e a cultura acumulados pela sociedade, com o fim de preservá-la; por outro lado, constitui espaço de manifestaçáo e desenvolvimento de seu potencial para criar novos significados, novos saberes e novas culturas, o que por sua vez concorre para transformar essa mesma sociedade.

Surgem assim, os pressupostos daquela que Gadotti (1987) chamou de urna "Pedagogia Dialética" -comprometida com os interesses das classes menos favorecidas e que se negava a ver a escola como instrumento para reproduçáo da estrutura social vigente. Essa posiço é assim expressa por Snyders (1977):

A escola é terreno em que se defrontarn as forças do progresso e as forças conservadoras, $\mathrm{O}$ que se passa na escola reflete a exploraçáo e a luta contra a exploraçáo. Ela é simultaneamente reproduçáo das estruturas existentes, correia de transmissáo da ideologia oficial, mas também arneaça ordem estabelecida e possibilidade de libertaço. A escola é urna instabilidade, mais ou menos aberta, a nossa açao (p. 106).

De fato, os preceitos básicos da pedagogia dialética, em oposiçáo à concepçao reprodutivista, reconhecem a existéncia de conflitos no espaço escolar mas acreditam nas possibilidades de enfrentá-los e assumem um compromisso com a libertaçao - a transformaçáo social. Para tanto, consideram os teóricos críticos que o processo ensinoaprendizagem náo pode ser desvinculado da realidade social e dos condicionantes históricos presentes na experiéncia de vida dos alunos. Ou seja, a aço pedagógica crítica 
e transformadora deve integrar-se à realidade concreta do aluno, buscando transformála.

Nessa concepçao, os conteúdos trabaihados precisam estar relacionados com a experiéncia e com os conhecimentos já dominados pelo aluno. Numa relaçao pedagógica dialética, ao mesmo tempo que novos temas sáo apresentados, devem ser (re)elaborados pelo aluno num processo de reflexáo e em confronto com os conhecimentos que já sao de seu domínio. A última etapa do processo é a aplicaçao dos conhecimentos aprendidos (ou reelaborados) sobre a realidade, no sentido de transformá-la.

Naquele momento, sob a influéncia dos pressupostos da pedagogia dialética, entendemos que o planejamento, tanto do ensino presencial como do ensino a distáncia, nao poderia perder de vista a realidade socio-cultural e educacional da comunidade que estava sendo atendida. Além de contemplar as características da comunidade, seria preciso também conhecer o perfil de cada um dos alunos. Que conhecimentos ele já dominava e quais deveriam ser explorados como os nós da rede de significados que sería tecida em confronto com os novos temas apresentados?

Conhecer o aluno visando a oferecer-Ihe tratamento diferenciado e conhecer o contexto sócio-cultural em que ele vive e atua como profissional é uma antiga preocupaçáo nossa. Neste trabalho, descrevemos a forma como desde entao temos levantado o perfil de cada um dos nossos alunos, ao mesmo tempo que extraímos deles informaçóes sobre o contexto em que trabalham e/ou estudam. Indicamos também, como o levantarnento dos perfis dos alunos tem feito parte de cursos a distáncia semi-presenciais da Universidade Salgado de Oliveira - UNIVERSO, onde ternos atuado como tutores, e ainda como os conhecimentos obtidos tém sido valiosos auxiliares no ensino e na pesquisa.

\section{LEVANTAMENTO DO CONTEXTO E DO PERFII DO ALUNO}

Quem é o nosso aluno? O que ele sabe? O que deseja saber? Quais sao os problemas profissionais que ele enfrenta no dia-a-dia? Quais sAo suas reais necessidades? Como poderemos ajudá-lo objetivamente a encontrar-se como pessoa e a tornar-se melhor profissional?

Essas questóes nos preocupavam quando, na década de 80, iniciamos como instrutores da UNIVERSO, a fase presencial de um curso de Especializaçáo á distancia, para Supervisores Escolares do Estado de Goiás, na Regiao Centro- Oeste do Brasil, caracterizada pela baixa densidade demográfica e pela economia essencialmente rural. Para nós que vínhamos de uma rnetrópole da Regiao Sudeste (a UNIVERSO tem sua sede no Estado do Rio de Janeiro, que dista mais de $1000 \mathrm{~km}$ da capital de Goiás), cidade das mais populosas de urna regiao altamente industrializada, aquele era um mundo com o qual nao estávamos familiarizados. Percebemos entao que, para atuar naquele curso, além de nossa experiéncia e formaçáo, precisávamos conhecer o contexto em que trabalhavam e viviam nossos alunos, de onde vinham e onde queriam chegar.

Assim, em nosso prirneiro contato com o grupo de cerca de 100 (cern) alunos, habitantes de diversos municipios do Estado de Goiás, aplicamos dois instrumentos para 
coleta de dados. Inicialmente, preenchiam uma ficha cadastro com seus dados pessoais, educacionais e profissionais, declarando idade, sexo, local de residéncia, renda familiar, formaçáo, experiéncia profissional, condiçóes de trabalho, expectativas com relaçáo ao curso, conhecimentos já dominados e bibliografia conhecida sobre o tema que iríamos tratar.

O outro instrumento era uma folha de papel com espaço em branco, onde solicitávamos que o aluno narrasse um fato ou uma situaçáo-problema realmente vivenciada por ele no contexto escolar em que trabalhava.

Tabulados os dados da ficha cadastro, além do perfil individual, estava traçado o perfil do grupo, com informaçóes sócio-culturais, económicas, escolar e profissional, assim como estavam identificadas as expectativas que deveriam ser preenchidas pelo curso. Desse modo estavam respondidas as questóes que nos afligiam, isto é, conhecíamos o grupo e cada um dos alunos, os conhecimentos que já eram de seu domínio, o que esperavam e o que precisavam aprender.

A coletánea de casos/situaçóes-problema extraída das narrativas mostrou-se preciosa fonte de informaçóes sobre a realidade educacional e profissional do contexto em que o aluno exercia suas atividades, permitindo identificar as principais categorías de problemas profissionais típicas da regiáo, as áreas geográficas em que esses problemas incidiam, constituindo apoio inestimável para o estabelecimento dos objetivos das aulas, a seleçáo de textos, a elaboraçáo de provas e exercícios, e a formulaçáo de exemplos durante as exposiçóes teóricas e as propostas de atividades práticas.

\section{APLICAÇÓES PRÁTICAS DAS INFORMAÇÓES}

Uma vez identificado o perfil dos alunos e caracterizado o contexto, foi possível "individualizar" nossos procedimentos didático-pedagógicos. A partir dos dados sobre o dominio do conteúdo sendo ensinado, ou seja, dos assuntos que o aluno dominava com mais facilidade $\mathrm{cm}$ contrapartida aos assuntos nos quais ele nao atingira ainda um nível satisfatório, foi possível estabelecer a seqüéncia de exercícios a serem propostos, que variavam conforme as dificuldades encontradas pelo mesmo. Outro exemplo prático de individualizaçáo dos cursos conforme o perfil socio-cultural do aluno/grupo, relacionou-se com a escoiha de textos específicos, temas dos exercícios, e questóes de avaliaçáo a fim de que refletissem a realidade local.

Como ilustraçáo de uso de textos específicos, podemos citar a proposta apresentada por Monat e Bezerra (1996) na construçao de um conjunto de charadas (em inglés "riddles") para o ensino de lógica para adolescentes. Nesta proposta, os alunos se defrontam com exercícios, baseados em situaçóes do seu convívio social, que exigem capacidade lógica e conhecimento da tabela verdade, para que se alcance a soluçao. Cada situaçáo envolve um problema que pode ser descrito pela lógica de primeira ordem. Tal problema, ern termos de sua formulaço $\mathrm{cm}$ lógica, náo se altera. No entanto, o texto que descreve a situaçáo varia conforme o perfil levantado entre os alunos. Desta forma, uma charada envolvendo adolescentes da classe média de urna metrópole brasileira, pode descrever situaçóes onde os jovens estáo envolvidos com "shopping-centers", "danceterias", "video-games", etc. O mesmo problema, apresentado para urna turma de alunos de um distrito agrário de urna cidade de menor porte, envolvena outros elementos narrativos, relativos á vida ern fazendas, cooperativas agrícolas, e festas rurais. 
Desde aquele primeiro curso, constatamos que a coletánea de situaçóes-problema poderia ser útil como material didático no ensino á distáncia e, face aos bons resultados obtidos, passamos a iniciar o trabalho tutorial sempre com a mesma tarefa: aplicaçáo da ficha cadastro para obter o perfil dos alunos e solicitaçáo da descriçáo de uma situaçáoproblema realmente vivenciada no seu contexto profissional. A sistemática foi repetida em diversos cursos, tais como Supervisáo Educacional, Administraçáo Escolar, Planejamento Educacional e Metodologia da Pesquisa.

O trabalho tornava-se muito mais objetivo e motivador, pois o interesse dos Supervisores aumenta sensivelmente quando é submetido a exercícios ou a questóes de avaliaçáo que exigem reflexáo sobre as questóes de currículo ou de orientaçáo pedagógica que lhe afetam diretamente. Administradores se mostram bastante empenhados quando recebem como tarefa a elaboraço de um plano de açáo centrado $\mathrm{cm}$ problemas que ele identifica com aqueles que afetam a gestáo da instituiçáo $\mathrm{cm}$ que trabalham.

Nas disciplinas que envolvem pesquisa científica, tanto nos cursos de Graduaçáo como nos de Pós-Graduaço (stricto e lato sensu), quando solicitamos que o aluno elabore um projeto de estudo, é comum que tenha dificuldade de encontrar de imediato um tema ou problema que sirva de ponto de partida para seu trabalho. Dentro da sistemática adotada, esta dificuldade é minimizada, pois o aluno é estimulado a estudar e a buscar soluçóes a partir da situaçáo-problema apresentada na sua própria narrativa. Geralmente essa sugestáo é aceita prontamente e com excelentes resultados, pois o fato de o aluno ter selecionado aquele caso já demonstra o foco de seu interesse/preocupaçáo e, além disso como o problema foi experienciado por ele, terá maior desembaraço $\mathrm{cm}$ refletir sobre seus componentes.

Um outro exemplo de problema trazido pelos instrutores para os quais lecionamos, demonstrou ser típico da ap1icaço do uso de computadores em sala de aula no Brasil. As situaçóes que sto encontradas neste tema, so de total radicalismo. Ou o computador é visto de urna forma muito refratária, ou, como no caso narrado por um dos instrutores, a escola decídiu que todo o processo de ensino tinha que ter o computador como elemento central. Neste caso, a situaço que nos Foi trazida era de urna escola onde os alunos "assistiam" o computador, vezes sem qualquer interaço com o mesmo, pois os responsáveis pelo estabelecimento de ensino acreditavam que estavam assim patrocinando um trabaiho atual e moderno.

Este exemplo mostra como urn levantamento prévio corn os alunos pode ser vital ao planejamento de um curso semi-presencial. Sabedor do relato deste aluno, o material voltado para Informática e Educaço centrou-se sobre como levar o estudante daquela escola a interagir com a máquina. $\mathrm{O}$ curso seria muito diferente caso a realidade local mostrasse escoJas temerosas na introduço de computadores, ou incapazes de instala-los, ou ainda professores sem dominio de elementos básicos da Informática. Neste caso, o trabaiho tena focalizado os Fundamentos da Informática.

Ainda nos cursos sobre técnicas de estudo e de pesquisa, com base nos casos narrados por um mesmo grupo podem ser desenvolvidas inúmeras atividades, tais como categorizaçao de dados, de eventos ou de problemas, elaboraço de quadros estatísticos, análise comparativa de incidéncia de problemas por área geográfica, aplicaço de técnicas de "análise de caso" e de "resoluçáo de problemas". 


\section{A CONTINUIDADE DA EXPERIÉNCIA}

A partir das primeiras experiéncias bem sucedidas, adotamos no ensino á distáncia a sistemática de levantarnento do perfil do aluno e de situaçóes-problema vivenciadas por ele. A prática foi utilizada com cursistas de diferentes municipios brasileiros, situados nos Estados de: Goiás (na Regiáo Centro-Oeste), So Luiz do Maranháo (na Regiáo Norte), Espirito Santo, Minas Gerais e no Rio de Janeiro (na Regio Sudeste). Estas regióes representam contextos sócío-económicos e realidades culturais e educacionais das mais diversas.

Mais recentemente (1997/1998), tivemos oportunidade de participar como tutores do projeto de ensino á distáncia promovido pela Universidade de Brasília (UnB) e Cátedra UNESCO de Educaçáo a Distáncia, que também se utilizou de casos reais como conteúdo de exercícios e na avaliaçao da aprendizagem. No ato da inscriçáo do Curso de Especializaçao em Avaliaçáo no ensino Superior (a Distáncía) o candidato deveria narrar um caso real envolvendo um problema de avaliaçáo em instituiçóes de ensino superior. Dessa sistemática resultou a reuniáo de 840 casos ocorridos em diversos Estados do Brasil, correspondendo ao número de alunos inscritos no curso.

Os 840 casos foram grupados em áreas por similaridade temática (Sousa, 1997), e desse grupamento foram selecionados 24 casos, isto é, trés casos para cada urna das oito disciplinas do curso, a saber: Técnicas e Instrumentos de Ayaliaçáo; Avaliaçáo no Ensino Superior; Avaliaçáo de Políticas Públicas em Eduçáo; Avaliaçáo Institucional; Avaliaçáo de Currículos; Avaliaço de Disciplinas; Avaliaçio de Docentes e do Ensino; Acompanhamento e Avaliaçáo do Aluno.

Os 24 casos selecionados foram dramatizados e transformados em vídeos, produzidos pelo Centro de Produçáo Cultural e Educativa da UnB, e enviados para as bibliotecas das instituiçóes que tinham alunos matriculados no Curso, para consulta e/ou empréstimo. Após o estudo dos temas nos módulos impressos, os alunos deveriam aplicar os ensinamentos teóricos adquiridos no "estudo dos casos" contidos nos vídeos. Para tanto, no início do curso, em encontro presencial, os alunos receberam instruçóes sobre a metodologia de "estudo de casos" e de "resoluçáo de problemas" (Sousa, 1997).

Outros "casos" foram selecionados para serem utilizados na elaboraço das provas escritas que avaliavam a aprendizage do aluno ao final do estudo de cada uma das disciplinas. As provas consistiam na análise de casos e/ou em questóes de aplicaçáo das teorías estudadas na soluçáo dos casos.

\section{COMENTÁRIOS FINAIS}

Em suma, a prática do levantamento do perfil do aluno e do levantamento de situaçóes.problema que representem a realidade concreta no ensino a distáncia tem se mostrado excelente auxiliar nas atividades de ensino, de avaliaçao e de pesquisa, podendo ser aperfeiçoada para incluir novas situaçóes para sua aplicaçao e para o aproveitamento das informaçóes obtidas. 
Desde o primeiro momento, percebemos o quanto estávamos aprendendo sobre outros contextos sócio-culturais e educacionais e continuamos a explorar a prática do levantamento do perfil do aluno e a colecionar os "casos" narrados buscando um domínio maior e melhor da sua realidade.

Conhecendo melhor o aluno e o seu contexto podemos responder com mais firmeza aos seus anseios e as suas necessidades. O trabaiho se torna mais fácil, mais objetivo, mais interessante, mais efetivo. Crescemos nós. Cresce o aluno.

\section{REFERENCIAS BIBLIOGRÁFICAS}

ALTHUSSER, L. (s/d) Ideologia e aparelhos ideológicos do estado. Lisboa: Editorial Presença.

BAUDELOT, C. \& ESTABLET, R. (1971) L' école capitaliste en France. Paris: François

Maspero.

BOURDIEU, P. \& PASSERON, J-C. (1970). La reproduction: éléments pour une théorie du systme d'enseignement. Paris: Minuit.

GADOTTI, MOACIR. (1987) Concepçao dialética da educaçao: um estudo introdutório. Sáo Paulo: Cortez / Autores Associados.

MONAT, ANDRÉ \& BEZERRA, APRÍGIO (1996). Sistema inteligente para ensino de conceitos lógicos. Cadernos de Resumos. Workshop de Educaçáo e Tecnologia. Nova Friburgo, agosto de1996.

SAVIANI, D. (1987) Escola e democracia : teorias da educaçao, curvatura da vara, onze teses sobre educaçao e política. Coleçáo Polémica do Nosso tempo, 5. So Paulo: Cortez: Autores Associados.

SINYDERS, GEORGES (1977). Escola, classe e luta de classes. Lisboa: Moraes.

SOUSA, EVA c.b. MACHADO DE. (Org.). (1997). Curso de especializaçao em Avaliaçao a distáncia: Guia do Aluno. Brasília: Universidade de Brasília/Catedra Unesco de Educaçáo a Distáncia.

\section{PEFIL ACADÉMICO-PROFISSIONAL DOS AUTORES}

Nelly de Mendonça Moulin. Professora Titular da Universidade Salgado de Oliveira UNIVERSO. Doutora em Educaçao pela University of California at Los Angeles, USA. Mestre cm Educaç8o pela Universidade Federal do Rio de Janeiro - UERJ. Especialista em Educaçao a Distáncia pela Universidade Católica de Brasilia.

Vem atuando no campo da Educaçáo a Distáncia desde a década de 80 e tem investigado e publicado sobre a comunicaçáo escrita e sobre a avaliaçáo da aprendizagem no ensino a distáncia. 
André Monat é Professor Titular da Universidade Salgado de Oliveira - UNIVERSO. Doutorou-se em Computer Science and System Engineering pela University of East Anglia, Reino Unido tendo desenvolvido tese sobre Inteligéncia Artificial. Tem o curso de mestrado (Mphill) pela COPPE/UFRJ (Universidade Federal do Rio de Janeiro) em 1988 onde defendeu tese sobre sistemas especialistas. Tem desenvolvido trabalhos sobre aplicaçóes da Internet em ensino colaborativo para cardiologia, com o apoio do Conselho Nacional de Pesquisas - CNPq. Seus interesses incluem também elahoraçáo de cursos virtuais e de software educativo que se utilize de conceitos advindos da Inteligéncia Artificial.

\section{Nelly Moulin}

André Monat

Universidade Salgado de Oliveira - UNIVERSO

Rua Lamban, 10

Trindade - Sao Gonçalo - Rio de Janeiro - RJ

CEP: 24456-570 BRASIL

e-mail:nmoulin@ibm.net \& monat@uerj.br

telfax: + 5521 553-1451 